\title{
Relationship between Voice Fatigue and Voice Assessment in Patients with Voice Disorders and Applicability of Voice Fatigue Index in Korean Version
}

\author{
Young Ae Kang ${ }^{1,2}$, Jae Won Chang ${ }^{1,2}$, and Bon Seok Koo ${ }^{1,2}$ \\ ${ }^{I}$ Departments of Otolaryngology-Head and Neck Surgery, ${ }^{2}$ Research Institute for Medical Sciences, School of Medicine, \\ Chungnam National University, Chungnam National University Hospital, Daejeon, Korea
}

\section{음성장애환자 대상 음성피로와 음성평가 간 상관 및 음성피로도 설문(Voice Fatigue Index)의 임상적용}

강영애 ${ }^{1,2} \cdot$ 장재원 ${ }^{1,2} \cdot$ 구본석 ${ }^{1,2}$

충남대학교 의과대학 충남대학교병원 이비인후-두경부외과학교실, ${ }^{1}$ 의학연구소 ${ }^{2}$

\author{
Received December 13, 2016 \\ Revised January 20, 2017 \\ Accepted January 20, 2017 \\ Address for correspondence \\ Bon Seok Koo, MD, PhD \\ Department of Otolaryngology- \\ Head and Neck Surgery, \\ School of Medicine, \\ Chungnam National University, \\ Chungnam National University \\ Hospital, 282 Munhwa-ro, Jung-gu, \\ Daejeon 35015, Korea \\ Tel $+82-42-280-7695$ \\ Fax $+82-42-253-4059$ \\ E-mail bskoo515@cnuh.co.kr
}

Background and Objectives Vocal fatigue is a symptom and a term that has been frequently used in the clinical study. Although a recently developed vocal fatigue index (VFI), a self-report questionnaire that reliably identifies vocal fatigue patients, provides detailed characteristics of the symptom, there has been no study about the association between VFI and other voice assessment parameters. This study aimed to investigate whether there is a relationship between VFI and the established voice assessment in Korean patients.

Subjects and Method Two hundred fifty-seven patients with voice disorders (mean age, $49.48 \pm 14.34 ; 145$ male and 112 female) undertook the voice assessment that consisting of perceptual judgment [Grade, Roughness, Breathiness, Asthenia, Strain (GRBAS) Scale], acoustic and aerodynamic analysis, and voice handicap index (VHI) questionnaire. All patients validated using VFI. Correlation analysis between each voice assessment and VFI was conducted. Results There were statistical significances between items of voice assessment and VFI Among the GRBAS Scale, G, B, A, S and a number of acoustic measures were associated with vocal fatigue. In particular, these features were prominent in men. As the score of VFI increased, the sound pressure level during voicing and the phonation time from aerodynamic measures were decreased while the mean pitch was increased. In addition, VFI was closely correlated with pre-existing self-report questionnaire and VHI in both gender.

Conclusion These findings suggest that VFI has a significant association with pre-established voice assessment. Therefore, VFI can be used as a reliable tool for identifying and validating vocal fatigue in Korean.

Korean J Otorhinolaryngol-Head Neck Surg 2017;60(5):232-42

Key Words Korean version of voice fatigue index · Voice assessment · Voice disorders · Voice fatigue index.

\author{
서 론 \\ 피로도 유무에 따른 음성변화 연구들이 이루어졌고 임상 \\ This is an Open Access article distributed under the terms of the Creative Commons \\ Attribution Non-Commercial License (http://creativecommons.org/licenses/by-nc/4.0) \\ which permits unrestricted non-commercial use, distribution, and reproduction in any \\ medium, provided the original work is properly cited.
}

에서 음성피로(vocal fatigue)라는 용어가 자주 언급됨에도 본 용어의 정의 및 기전에 대해서 합의된 내용은 없다. ${ }^{1-3)}$ 많은 환 자들이 주관적으로 음성피로를 호소하지만, 객관적 방법으로 이를 확증할 방법은 아직 보고되지 않았다. 음성피로와 관련 된 증상에는 음질 저하, 음성 상실, 음도 일탈(pitch break), 좁 은 음역대역, 호흡 조절능력 저하, 목/어깨 긴장, 목구멍 피로 
도, 빈번한 목청 가다듬기를 들 수 있다.) 이는 임상에서 흔하 게 접할 수 있다.

용어의 정의가 합의되지 않았지만 분명한 점은 음성피로는 생리학적(physiologic), 청지각적(perceptual), 음향적(acoustic) 측면에서 후두 기능의 부정적인 변화를 초래한다는 점이 다.) 생리학적 관점에서 음성피로는 후두 근육피로(laryngeal muscle fatigue)와 후두 점막피로(laryngeal tissue fatigue)로 나눌 수 있다. ${ }^{5)}$ 일정한 짧은 기간 동안의 근수축의 속도 감소 로 유발되는 후두 근육피로는 성대의 과도한 근수축을 유발 하고, 후두 점막피로는 발성으로 인한 점막(lamina propria)의 일시적 변화 및 상처에 의해서 발생하여 발성외상(phonotrau$\mathrm{ma})$ 이라고도 불린다.

음성피로의 기전으로 신경근 피로(neuromuscular fatigue), 성대의 점액 증가(increased vocal fold viscosity), 혈류 감소 (reduced blood circulation), 점막 긴장도(nonmuscular tissue strain), 호흡근의 피로(respiratory muscle fatigue)가 거론된 다. ${ }^{1)}$ 신경근 피로란, 반복되는 자극에 후두의 안정적 유지 및 성대근의 긴장도 유지 능력의 감소를 의미한다. 이러한 능력 감소가 음성피로를 유발한다. 또한 장시간의 발성은 성대 내 점액 구성성분을 변화시켜 성대의 점성도를 증가시키며 성대 경직(stiffness)을 초래한다. 또한 성대진동 시 마찰을 증가시 켜 결과적으로 열에너지를 손실시킨다. 열에너지 손실은 발성 시 공기역학 에너지가 물리적 소리에너지로 바뀌는 데 더 많 은 에너지 소모가 유발되어 음성피로를 높인다. 탈수(dehydration) 된 성대상태에서 더 높은 발성역치압력(phonation threshold pressure)이 필요하다는 보고와 같은 맥락이다. ${ }^{6}$ 또 다른 공기역학적 관점에서 음성피로는 공기의 양(airflow) 을 줄이고 압력을 증가시켜 공기저항을 변화시킨다. ${ }^{4)}$ 성대근 검사(electromyography)에서 음성피로도에 따라 근 신호가 크게 증가되어 ${ }^{2}$ 음성피로는 성대근 긴장도에도 영향을 미치 는 것을 알 수 있다. 흥미로운 점은 성별에 따른 피로도 반응 양상이 달랐는데, ${ }^{7)}$ 남성은 정신적 피로도에 따라 음성의 음 향적 변수가 부정적으로 변한 반면, 여성은 신체적 피로도에 따라 음향변수의 변화보다는 주관적 평가에 영향을 받는 것 으로 파악되었다. 또한 성별에 관계없이 직업적 음성 사용자 인 교사들의 경우, 음향적 변수 변화를 보이는 동시에 주관적 평가에 더욱 민감하여 결국 사회활동에서 음성사용이 제약된 다고 하였다. ${ }^{8)}$ 음성피로는 실질적으로 성대진동 양상도 변화 시키는데, 음성피로를 느끼는 여성 10 명 중 6 명의 성대진동에 서 앞성문틈(anterior glottal chink)이 관찰되었고, 음성피로 에 따라 성대진동모양이 방추형(spindle-shaped)으로 변하였 다. 음성피로가 높은 고음발성에서 이러한 성대진동 변화는 더욱 두드러졌다. ${ }^{6}$
이렇듯 여러 음성피로 관련 연구의 보고와 임상에서 관찰되 는 음성피로는 음성산출 및 생활전반에 부정적 영향을 주는 것이 분명하므로 이를 판별하고 치료대상으로 삼아야 할 것 이다. 본 연구에서 2015년 보고된 음성피로도 설문지(vocal fatigue index, $\mathrm{VFI})^{9}$ 와 기존의 음성평가 항목인 청지각, 음향, 공기역학, 주관적 평가 간 관계를 검증하며 활용가능성을 확 인하고자 한다. VFI는 5점 척도(0 4점) 19항목으로 총점 76 점까지 채점되며 점수가 높을수록 음성피로도가 높다고 해 석한다.

\section{대상 및 방법}

\section{대 상}

2015년 10월부터 2016년 7월까지 이비인후과 전문의로부터 후두 내시경 검사로 음성장애환자로 진단 받고, 미세후두수 술(laryngomicrosurgery, LMS)이 예정된 328명을 모집하여 음성검사와 VFI를 실시하였다. 음성평가 항목은 청지각 평 가, 음향 평가, 공기역학 평가, 주관적 설문지로 구성하였다.

328 명 중 청력 손실자 및 보청기 착용자, 호흡기 질환자, 우 울증 약 복용자, 과거 LMS 수술 받은 자, 18세 이하 소아, 임 산부, 갑상선 기능 이상자, 갑상선 수술 및 방사선 치료를 받 은 자, 인지 저하자, 음성치료를 받은 자, 주관적 설문지 거부 자를 제외하여 257 명을 선정하였다.

성대병변은 큰 병변을 기준으로 분류하였으며, 257 명 중 성 대용종, 성대결절, 백반증(159명), 성대마비(11명), 역류성 인후 두염(7명), 근긴장성 발성장애(3명), 연축성 발성장애(5명), 유 두종 및 육아종(3명), 성대구증(4명), 성대부종(7명), 성대낭종 (17명), 수술 이후 음성치료를 위한 재음성검사(39명), 성대병 변은 없으나 음성사용 불편감 호소(2명)로 이루어졌다. 전체 대 상의 연령평균은 49.48 \pm 14.34 세, 연령범위는 19 83세이며, 남 녀(평균연령, 연령범위) 각각 145명(50.98 \pm 15.23 세, 19 83세), 112명(47.12 \pm 12.92 세, 19 74세)이었다(Table 1). 본 연구는 본 병원의 임상연구심의위원회의 승인(IRB No. CNUH 2016-06013)하에 후향적 연구로 이루어졌다.

\section{방 법}

음성평가 항목 중 임상가의 청지각 평가는 Grade, Roughness, Breathiness, Asthenia, Strain(GRBAS) 척도(0 정상, 3 심각)를 사용하였다. 환자에게 모음/아/ 발성과 표준화된 '가 을 문단을 읽히고, 음성장애 치료 실무 경험이 5년 이상인 1급 언어치료사가 실시간으로 평가하였다. 모음과 문단읽기에서 음질 차이가 날 경우 문단읽기를 기준으로 기록하였다.

음향 평가는 평안한 모음/아/의 4초 발성을 선택하여 multi- 
Table 1. Demographic data of study patients

\begin{tabular}{lcc}
\hline \multicolumn{1}{c}{ Variables } & Number (\%) & Gender (M:F) \\
\hline Number \& age & & $145: 112$ \\
No. of patients & $257(100)$ & $50.98 \pm 15.23: 47.12 \pm 12.92$ \\
Mean age (years) & $49.48 \pm 14.34$ & $19-83: 19-74$ \\
Age range (years) & $19-83$ & $93: 66$ \\
Diagnosis & $159(61.9)$ & $5: 6$ \\
Vocal polyp, vocal nodules, leukoplakia & $11(4.3)$ & $2: 5$ \\
Vocal palsy & $7(2.7)$ & $3: 0$ \\
Laryngopharyngeal reflux & $3(1.2)$ & $0: 5$ \\
Muscle tension dysphonia & $5(1.9)$ & $3: 0$ \\
Spasmodic dysphonia & $3(1.2)$ & $2: 2$ \\
Papilloma, granuloma & $4(1.6)$ & $3: 4$ \\
Sulcus vocalis & $7(2.7)$ & $11: 6$ \\
Vocal edema & $17(6.6)$ & $22: 17$ \\
Vocal cyst & $39(15.2)$ & $1: 1$ \\
Post-LMS & $2(0.8)$ & \\
Functional dysphonia & & \\
\hline
\end{tabular}

LMS: laryngomicrosurgery

dimensional voice program(MDVP, Model 5105; KayPentax Inc., Lincoln Park, NJ, USA)을 사용하여 34개 변수를 분 석하였으며, 최대발성이 4초 미만인 경우는 묵음 구간을 제 외하고, 전체 발성길이를 분석에 적용하였다.

MDVP의 34개 변수는 총 8범주로 나눌 수 있다. 기본주파 수 관련 측정치(F0-related measurements), 주파수변동 관 련 측정치(frequency perturbation measurements), 진폭변 동 관련 측정치(amplitude perturbation measurements), 진 전 관련 측정치(tremor measurements), 음성일탈 관련 측정 치(voice break measurements), sub-harmonics 관련 측정치 (sub-harmonics measurements), 음성의 불규칙성 관련 측정 치(voice irregularity measurements), 소음 관련 측정치(noise measurements)로 나뉜다. ${ }^{10)}$

본 연구에서는 변동이 적은 변수들의 통계결과 비교를 용 이하게 하기 위해서 음성일탈, sub-harmonics, 음성 불규칙성 관련 측정치를 하나의 범주(voice break, sub-harmonic \& voice irregularity measurements)로 묶고, 소음과 진전을 또 다른 범주(noise \& tremor evaluation measurements)로 묶 어 총 5 범주로 재분류하였다. 34 개 변수 중 통계에 적용한 27 개 변수를 선택하여 범주별로 정리하면 다음과 같다. ${ }^{a}$

1) 5 개의 주파수 관련 측정치(원어, 약어, 단위): 기본주파 수(average fundamental frequency, F0, Hz), 분석된 기본주 파수의 평균(mean fundamental frequency, $\mathrm{mF0}, \mathrm{Hz}$ ), 기본

a한글 표기는 각 변수의 개념을 바탕으로 독자들의 이해를 돕기 위해 기술한 것이며, 음성전문가(음성학, 음성공학, 언어병리학 등)들의 합의 를 거친 한글용어가 아님을 미리 밝혀둔다.
주파수의 표준편차(standard deviation of $\mathrm{FO}, \mathrm{STD}, \mathrm{Hz}$ ), 분 석된 샘플 길이(length of analyzed sample, Tsam, sec.), 음 도길이의 총수(total number detected pitch, PER).

2) 6 개의 주파수변동 관련 측정치(원어, 약어, 단위): 절대 적 주파수변동률(absolute jitter, Jita, $\mu \mathrm{s}$ ), 상대적 주파수변 동률(jitter percent, Jitt, \%), 3주기 내 상대적 주파수변동률 (relative average perturbation, RAP, \%), 5 주기 내 상대적 주 파수변동률(pitch perturbation quotient, PPQ, \%), 55주기 내 평탄화된 주파수변동률(smoothed pitch perturbation quotient, sPPQ, \%), 기본주파수의 상대적 표준편차(fundamental frequency variation, $\mathrm{vF0}, \%$ ).

3) 5 개의 진폭변동 관련 측정치(원어, 약어, 단위): 상대적 진 폭변동률(shimmer in $\mathrm{dB}, \mathrm{ShdB}, \mathrm{dB}$ ), 상대적 진폭변동률 (shimmer percent, Shim, \%), 11주기 내 진폭변동률(amplitude perturbation quotient, $\mathrm{APQ}, \%), 55$ 주기 내 진폭변동률 (smoothed amplitude perturbation quotient, sAPQ, \%), 진 폭의 상대적 표준편차(peak-to-peak amplitude variation, vAm, \%).

4) 6 개의 음성 불규칙성 관련 측정치(원어, 약어, 단위): 음성 일탈 정도(degree of voice break, DVB, \%), non-harmonics 의 횟수(number of unvoiced segments, NUV), sub-harmonics의 발생길이 정도(degree of sub-harmonics, $\mathrm{DSH}$, \%), subharmonics의 횟수(number of sub-harmonic segments, NSH), non-harmonics의 길이 정도(degree of voiceless, DUV, \%), 음성일탈 횟수(number of voice breaks, NVB).

5) 5 개의 소음과 진전 관련 측정치(원어, 약어, 단위): 소음대 
배음 비율(noise to harmonic ratio, NHR), 배음과 비배음 간 비율의 평균치(voice turbulence index, VTI), 저-고주파수 대 역의 배음 에너지 비율(soft phonation index, SPI), 주파수 진 전 비율(F0-tremor intensity index, FTRI, \%), 진폭 진전 비 율(amplitude tremor intensity index, ATRI, \%).

공기역학 평가는 Phonatory Aerodynamic System(PAS Model 6600; KayPentax Inc.)을 사용하여 임상에서 기본적 으로 널리 분석되는 세 과제(폐활량 과제, 최대모음연장발성
과제, 발성효율역치 과제)를 측정하였다. 분석 변수는 총 9개 이며 호기량(expiratory volume, FVC), 발성 시 음압(mean sound pressure level during voicing, PHODB), 평균음도 (mean pitch, MEAP), 최대연장발성시간(phonation time, $\mathrm{PHOT}$ ), 평균호기류율(mean expiratory airflow, MEAF), 평균 성문하압(mean peak air pressure), 표준 호기류율(target airflow, TARF), 공기역학저항(aerodynamic resistance), 공 기역학효율(aerodynamic efficiency)이다.

Table 2. Analysis parameters list

\begin{tabular}{|c|c|c|}
\hline Category & Tools \& task & Parameter \\
\hline Perceptual judgment & $\begin{array}{l}\text { Clinician's ear } \\
\text { - Vowel/a/ \& reading }\end{array}$ & GRBAS Scale \\
\hline Acoustic analysis & $\begin{array}{l}\text { MDVP } \\
- \text { Vowel/a/ phonation }\end{array}$ & $\begin{array}{l}\text { (1) FO-related measurements } \\
\text { - FO, mFO, STD, Tsam, PER } \\
\text { (2) Frequency perturbation measurements } \\
\text { - Jita, Jitt, RAP, PPQ, SPPQ, vFO } \\
\text { (3) Amplitude perturbation measurements } \\
\text { - ShdB, Shim, APQ, SAPQ, vAm } \\
\text { (4) Voice break, sub-harmonic \& voice irregularity measurements } \\
\text { - DVB, NUV, DSH, NSH, DUV, NVB } \\
\text { (5) Noise \& tremor evaluation measurements } \\
\text { - NHR, VTI, SPI, FTRI, ATRI }\end{array}$ \\
\hline Aerodynamic analysis & PAS & $\begin{array}{l}\text { (1) Vital capacity protocol } \\
\text { - FVC } \\
\text { (2) Maximum sustained phonation protocol } \\
\text { - PHODB, MEAP, PHOT, MEAF } \\
\text { (3) Voicing efficiency threshold protocol } \\
\text { - MPAP, TARF, ARES, AEFF }\end{array}$ \\
\hline Self-questionnaire & Patient's volition & $\begin{array}{l}\text { (1) } \mathrm{VHI} \\
-30 \text { items ( } 0-4 \text { point each) } \\
\text { (2) VFI } \\
-19 \text { items ( } 0-4 \text { point each) }\end{array}$ \\
\hline
\end{tabular}

F0: average fundamental frequency $(\mathrm{Hz}), \mathrm{mFO}$ : mean fundamental frequency $(\mathrm{Hz})$, STD: standard deviation of FO ( $\mathrm{Hz})$, Tsam: length of analyzed sample (sec.), PER: total number detected pitch, Jita: absolute jitter (\%), Jitt: jitter percent (\%), RAP: relative average perturbation (\%), PPQ: pitch perturbation quotient (\%), sPPQ: smoothed pitch perturbation quotient (\%), vF0: fundamental frequency variation (\%), ShdB: shimmer in dB (dB), Shim: shimmer percent (\%), APQ: amplitude perturbation quotient (\%), SAPQ: smoothed amplitude perturbation quotient (\%), vAm: peak-to-peak amplitude variation (\%), DVB: degree of voice break (\%), NUV: number of unvoiced segments, DSH: degree of sub-harmonics, NSH: number of sub-harmonic segments, DUV: degree of voiceless (\%), NVB: number of voice breaks, NHR: noise to harmonic ratio, VTI: voice turbulence index, SPI: soft phonation index, FTRI: FO-tremor intensity index, ATRI: amplitude tremor intensity index, FVC: expiratory volume (liters), PHODB: mean sound pressure level during voicing (dB), MEAP: mean pitch ( $\mathrm{Hz}$ ), PHOT : phonation time (sec.), MEAF: mean expiratory airflow (lit/sec.), MPAP: mean peak air pressure $\left(\mathrm{cmH}_{2} \mathrm{O}\right)$, TARF: target airflow (lit/sec.), ARES: aerodynamic resistance [ $\mathrm{cmH}_{2} \mathrm{O} /(\mathrm{I} / \mathrm{s})$ ], AEFF: aerodynamic efficiency (ppm), VHI: voice handicap index, VFI: vocal fatigue index, MDVP: multi-dimensional voice program, PAS: Phonatory Aerodynamic System, GRBAS: Grade, Roughness, Breathiness, Asthenia, Strain

Table 3. Results of Pearson correlation analysis between VFI and perceptual judgment

\begin{tabular}{|c|c|c|c|c|c|c|}
\hline \multirow{2}{*}{$\mathrm{VFI}$} & \multirow{2}{*}{ Pearson } & \multicolumn{5}{|c|}{ Perceptual judgment } \\
\hline & & G & $R$ & B & A & $S$ \\
\hline \multirow[t]{2}{*}{ Male $(n=145)$} & C.C. & 0.262 & 0.130 & 0.279 & 0.128 & 0.393 \\
\hline & $p$ & $0.001^{*}$ & 0.121 & $0.001^{*}$ & 0.126 & $<0.000^{\dagger}$ \\
\hline \multirow[t]{2}{*}{ Female $(n=112)$} & C.C. & 0.242 & 0.176 & 0.233 & 0.050 & 0.205 \\
\hline & $p$ & $0.010^{*}$ & 0.064 & $0.014^{*}$ & 0.603 & $0.031^{*}$ \\
\hline \multirow[t]{2}{*}{ Total $(n=257)$} & C.C. & 0.188 & 0.107 & 0.204 & 0.173 & 0.222 \\
\hline & $p$ & $0.003^{*}$ & 0.08 & $0.001^{\dagger}$ & $0.006^{+}$ & $<0.000^{\dagger}$ \\
\hline
\end{tabular}

$* p<0.05,{ }^{\dagger} p<0.01$. C.C.: correlation coefficient, VFl: vocal fatigue index, G: Grade, R: Roughness, B: Breathiness, A: Asthenia, S: Strain 
환자의 주관적 설문은 음성장애평가(voice handicap index, $\mathrm{VHI}$ 를 실시하였다.

검사 항목과 변수는 Table 2에 정리하였고, 이비인후과 전문 의 교정을 거쳐 번안한 VFI를 Appendix에 제시하였다.

\section{통계적용}

SPSS(version 22; IBM Corp., Armonk, NY, USA)를 사 용하여 VFI와 음성검사 하위 항목인 청지각 평가, 음향, 공기 역학, 주관적 설문 간 관계를 알아보기 위해 피어슨 상관분 석(Pearson correlation analysis)을 적용하였다.

\section{결 과}

\section{음성피로도와 청지각 평가 간 상관분석}

$\mathrm{VFI}$ 와 청지각 평가 간 상관분석 결과(Table 3), 전체 257명 을 대상으로 한 VFI 점수와 GRBAS 항목 간 $\operatorname{Grade}(p=0.003)$, $\operatorname{Breathiness}(p=0.001)$, Asthenia( $p=0.006), \operatorname{Strain}(p<0.000)$ 항목에서 통계적으로 유의미한 정적상관을 보였다. 성별을 나 눠 살펴보면 145 명의 남성군에서는 Grade $(p=0.001)$, Breathi$\operatorname{ness}(p=0.001), \operatorname{Strain}(p<0.000)$ 항목에서 유의미한 정적상관 을 보였고, 112 명의 여성군에서는 $\operatorname{Grade}(p=0.010)$, Breathiness ( $p=0.014), \operatorname{Strain}(p=0.031)$ 항목에서 정적상관을 보였다. 음 성피로도가 높을수록 음질은 저하되었다.

\section{음성피로도와 주관적 음성사용불편감 간 상관분석}

전체 257명에서 두 주관적 설문지(VFI, VHI) 간 강한 정적 상관을 보였다[correlation coefficient(C.C.) $=0.791, p<0.000]$. 이는 남성군(C.C. $=0.809, p<0.000)$ 과 여성군(C.C. $=0.766, p<$ $0.000)$ 각각에서도 강한 정적상관을 보였다. 그리고 여성보다 남성에서 주관적 설문 간의 상관이 더 높았다. VFI와 $\mathrm{VHI}$ 간 산점도를 Fig. 1에 도식화하였다.

\section{음성피로도와 음향 분석 간 상관분석}

음향변수 결과는 5항목별로 기술하였다(Table 4).

\section{기본주파수 관련 측정치}

전체 257명에서 F0(C.C. $=0.237, p<0.000), \mathrm{mF0}$ (C.C. $=$ $0.222, p<0.000)$, STD(C.C. $=0.232, p<0.000)$ 변수에서 유의 미한 정적상관을 보였고, Tsam(C.C. $=-0.186, p=0.003)$ 변수는 부적상관을 보였다. 성별을 나눠 보면, 남성군에서 STD(C.C.= $0.296, p<0.000)$ 변수는 정적상관을 보였지만, Tsam(C.C.= $-0.342, p<0.000), \mathrm{PER}(\mathrm{C} . \mathrm{C} .=-0.239, p<0.000)$ 변수는 부적 상관을 보였다. 여성군에서는 통계적으로 유의미한 상관관계

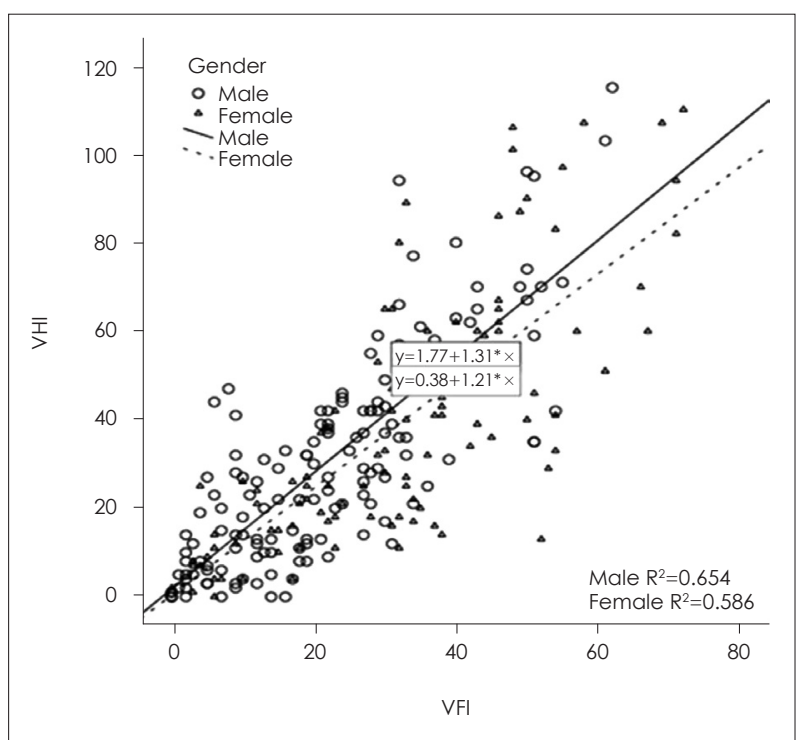

Fig. 1. Correlation plot between voice handicap index (VHI) and vocal fatigue index (VFI) in each gender. A circle indicates male and a triangle indicates female. The linear regression equations between $\mathrm{VHI}$ and $\mathrm{VFI}$ are $\mathrm{y}=1.77+1.31 \times\left(\right.$ adjusted $\mathrm{R}^{2}=0.654$ ) for male and $\mathrm{y}=0.38+1.21 \times\left(\right.$ adjusted $\left.\mathrm{R}^{2}=0.586\right)$ for female. $*$ marker in the linear regression equations indicates multiplication.

가 없었다. Tsam 변수는 발성길이를 의미하고, PER 변수는 일정 발성길이 내 주기성 수를 뜻하므로 남성군에서 음성피 로도가 높을수록 발성길이와 발성 내 주기성이 감소했다고 해석한다.

\section{주파수변동 관련 측정치}

전체 257명에서 $\operatorname{Jita}(C . C .=0.169, p=0.007)$, $\mathrm{Jitt}($ C.C. $=0.214$, $p=0.001)$, RAP(C.C. $=0.225, p<0.000)$, PPQ(C.C. $=0.205$, $p=0.001), \mathrm{sPPQ}($ C.C. $=0.162, p=0.009), \mathrm{vFO}($ C.C. $=0.220, p<$ $0.000)$ 모두 변수에서 유의미한 정적상관을 보였다. 남성군 에서 $\operatorname{Jita}(C . C .=0.276, p=0.001)$, $\operatorname{Jitt(C.C.~}=0.306, p<0.000)$, RAP(C.C. $=0.320, p<0.000), \mathrm{PPQ}($ C.C. $=0.293, p<0.000$ ), $\mathrm{sPPQ}(\mathrm{C} . \mathrm{C} .=0.265, p=0.001), \mathrm{vF0}(\mathrm{C} . \mathrm{C} .=0.326, p<0.000)$ 의 모든 변수가 유의미한 정적상관을 보인 반면, 여성군에서는 통계적으로 유의미한 상관관계가 없었다.

\section{진폭변동 관련 측정치}

전체 257명에서 $\operatorname{ShdB(C.C.=0.124,~} p=0.047)$, Shim(C.C.= $0.140, p=0.024)$ 변수는 유의미한 정적상관을 보였다. 남성군 에서 ShdB(C.C. $=0.204, p=0.014)$, Shim(C.C. $=0.221, p=$ 0.008), $\mathrm{APQ}($ C.C. $=0.197, p=0.017)$ 변수가 유의미한 정적상 관을 보인 반면, 여성군에서는 통계적으로 유의미한 상관관 계가 없었다. 
음성일탈, Sub-harmonics, 음성 불규칙성 관련 측정치

전체 257명에서 $\mathrm{DSH}(\mathrm{C} . \mathrm{C} .=0.196, p=0.002), \mathrm{NSH}(\mathrm{C} . \mathrm{C} .=$ $0.169, p=0.007)$ 변수가 유의미한 정적상관을 보였으며 남성 군에서 $\operatorname{DSH}($ C.C. $=0.253, p=0.002)$, DUV(C.C. $=0.214, p=$ 0.010), $\mathrm{NSH}($ C.C. $=0.199, p=0.016), \mathrm{NUV}($ C.C. $=0.179, p=0.031)$ 변수가 유의미한 정적상관을 보였다. 하지만 여성군에서는 통계적으로 유의미한 상관관계가 없었다.

\section{소음과 진전 관련 측정치}

전체 257명에서 $\operatorname{NHR(C.C.~}=0.176, p=0.005)$, VTI(C.C.= $0.198, p=0.001)$ 변수가 정적상관을 보인 반면, SPI(C.C. $=-0.223$, $p<0.000)$ 변수는 부적상관을 보였다. 남성군에서 $\mathrm{NHR}(\mathrm{C}$. C. $=0.267, p=0.001)$, VTI(C.C. $=0.282, p=0.001)$, FTRI(C.C. $=$ $0.236, p=0.005)$ 변수가 정적상관을 보였고, SPI(C.C. $=-0.164$, $p=0.048)$ 변수는 부적상관을 보였다. 하지만 여성군에서는 통

Table 4. Results of Pearson correlation analysis between VFI and acoustic analysis

\begin{tabular}{|c|c|c|c|c|c|c|}
\hline \multirow{3}{*}{ Acoustic parameters } & \multicolumn{6}{|c|}{ Pearson analysis with VFI } \\
\hline & \multicolumn{2}{|c|}{ Total $(n=257)$} & \multicolumn{2}{|c|}{ Male $(n=145)$} & \multicolumn{2}{|c|}{ Female $(n=112)$} \\
\hline & C.C. & $p$ & C.C. & $p$ & C.C. & $p$ \\
\hline \multicolumn{7}{|l|}{ F0-related } \\
\hline FO & 0.237 & $<0.000^{\dagger}$ & 0.066 & 0.429 & 0.077 & 0.420 \\
\hline mFO & 0.222 & $<0.000^{\dagger}$ & 0.029 & 0.728 & 0.062 & 0.518 \\
\hline STD & 0.232 & $<0.000^{\dagger}$ & 0.296 & $<0.000^{\dagger}$ & 0.143 & 0.132 \\
\hline Tsam & -0.186 & $0.003^{\dagger}$ & -0.342 & $<0.000^{\dagger}$ & -0.017 & 0.862 \\
\hline PER & 0.102 & 0.104 & -0.239 & $<0.000^{\dagger}$ & 0.056 & 0.559 \\
\hline \multicolumn{7}{|l|}{ Frequency perturbation } \\
\hline Jita & 0.169 & $0.007^{\dagger}$ & 0.276 & $0.001^{\dagger}$ & 0.126 & 0.185 \\
\hline Jitt & 0.214 & $0.001^{\dagger}$ & 0.306 & $<0.000^{\dagger}$ & 0.129 & 0.174 \\
\hline RAP & 0.225 & $<0.000^{\dagger}$ & 0.320 & $<0.000^{\dagger}$ & 0.130 & 0.171 \\
\hline$P P Q$ & 0.205 & $0.001^{\dagger}$ & 0.293 & $<0.000^{\dagger}$ & 0.122 & 0.199 \\
\hline sPPQ & 0.162 & $0.009+$ & 0.265 & $0.001^{\dagger}$ & 0.059 & 0.539 \\
\hline vFO & 0.220 & $<0.000^{\dagger}$ & 0.326 & $<0.000^{\dagger}$ & 0.105 & 0.269 \\
\hline \multicolumn{7}{|l|}{ Amplitude perturbation } \\
\hline ShdB & 0.124 & $0.047^{*}$ & 0.204 & $0.014^{*}$ & 0.071 & 0.460 \\
\hline Shim & 0.140 & $0.024^{*}$ & 0.221 & $0.008^{\dagger}$ & 0.095 & 0.320 \\
\hline$A P Q$ & 0.121 & 0.054 & 0.197 & $0.017^{*}$ & 0.095 & 0.321 \\
\hline SAPQ & 0.072 & 0.250 & 0.126 & 0.132 & 0.026 & 0.785 \\
\hline vAm & 0.043 & 0.495 & 0.112 & 0.180 & -0.038 & 0.694 \\
\hline \multicolumn{7}{|c|}{ Voice break, sub-harmonic \& voice irregularity } \\
\hline DVB & 0.037 & 0.552 & 0.093 & 0.265 & -0.013 & 0.895 \\
\hline DSH & 0.196 & $0.002^{\dagger}$ & 0.253 & $0.002^{\dagger}$ & 0.075 & 0.429 \\
\hline DUV & 0.121 & 0.053 & 0.214 & $0.010^{\dagger}$ & 0.060 & 0.527 \\
\hline NVB & -0.035 & 0.573 & -0.023 & 0.785 & -0.070 & 0.463 \\
\hline NSH & 0.169 & $0.007+$ & 0.199 & $0.016^{*}$ & 0.067 & 0.482 \\
\hline NUV & 0.094 & 0.131 & 0.179 & $0.031^{*}$ & 0.052 & 0.588 \\
\hline \multicolumn{7}{|l|}{ Noise \& tremor } \\
\hline NHR & 0.176 & $0.005^{\dagger}$ & 0.267 & $0.001^{\dagger}$ & 0.117 & 0.221 \\
\hline VTI & 0.198 & $0.001^{\dagger}$ & 0.282 & $0.001^{\dagger}$ & 0.126 & 0.185 \\
\hline SPI & -0.223 & $<0.000^{\dagger}$ & -0.164 & $0.048^{*}$ & -0.131 & 0.169 \\
\hline FTRI & 0.039 & 0.543 & 0.236 & $0.005^{\dagger}$ & -0.096 & 0.337 \\
\hline ATRI & 0.025 & 0.731 & 0.051 & 0.611 & -0.031 & 0.775 \\
\hline
\end{tabular}

$* p<0.05,+p<0.01$. F0: average fundamental frequency $(\mathrm{Hz}), \mathrm{mFO}$ : mean fundamental frequency (Hz), STD: standard deviation of FO (Hz), Tsam: length of analyzed sample (sec.), PER: total number detected pitch, Jita: absolute jitter (\%), Jitt: jitter percent (\%), RAP: relative average perturbation (\%), PPQ: pitch perturbation quotient (\%), sPPQ: smoothed pitch perturbation quotient (\%), VFO: fundamental frequency variation (\%), ShdB: shimmer in $d B(d B)$, Shim: shimmer percent (\%), APQ: amplitude perturbation quotient (\%), sAPQ: smoothed amplitude perturbation quotient (\%), vAm: peak-to-peak amplitude variation (\%), DVB: degree of voice break (\%), NUV: number of unvoiced segments, DSH: degree of sub-harmonics, NSH: number of sub-harmonic segments, DUV: degree of voiceless (\%), NVB: number of voice breaks, NHR: noise to harmonic ratio, VTI: voice turbulence index, SPI: soft phonation index, FTRI: FO-tremor intensity index, ATRI: amplitude tremor intensity index, C.C.: correlation coefficient, VFI: vocal fatigue index 
Table 5. Results of Pearson correlation analysis between VFI and aerodynamic parameters

\begin{tabular}{|c|c|c|c|c|c|c|}
\hline \multirow{3}{*}{$\begin{array}{c}\text { Aerodynamic } \\
\text { parameters }\end{array}$} & \multicolumn{6}{|c|}{ Pearson analysis with VFI } \\
\hline & \multicolumn{2}{|c|}{ Total $(n=257)$} & \multicolumn{2}{|c|}{ Male $(n=145)$} & \multicolumn{2}{|c|}{ Female $(n=112)$} \\
\hline & C.C. & $p$ & C.C. & $p$ & C.C. & $p$ \\
\hline FVC & -0.041 & 0.510 & 0.211 & $0.011^{*}$ & 0.045 & 0.638 \\
\hline PHODB & -0.215 & $0.001^{\dagger}$ & -0.122 & 0.143 & -0.248 & $0.008^{\dagger}$ \\
\hline MEAP & 0.181 & $0.004^{\dagger}$ & -0.031 & 0.713 & 0.024 & 0.801 \\
\hline PHOT & -0.137 & $0.028^{*}$ & -0.122 & 0.145 & -0.024 & 0.798 \\
\hline MEAF & 0.049 & 0.430 & 0.226 & $0.006^{\dagger}$ & -0.036 & 0.703 \\
\hline MPAP & 0.073 & 0.241 & 0.152 & 0.051 & 0.066 & 0.487 \\
\hline TARF & 0.073 & 0.241 & 0.212 & $0.011^{*}$ & 0.003 & 0.973 \\
\hline ARES & 0.038 & 0.548 & -0.061 & 0.461 & 0.016 & 0.865 \\
\hline AEFF & -0.055 & 0.378 & -0.068 & 0.417 & -0.101 & 0.291 \\
\hline
\end{tabular}

$* p<0.05, \dagger_{p}<0.01$. FVC: expiratory volume (liters), PHODB: mean sound pressure level during voicing (dB), MEAP: mean pitch (Hz), PHOT: phonation time (sec.), MEAF: mean expiratory airflow (lit/sec.), MPAP: mean peak air pressure $\left(\mathrm{cmH}_{2} \mathrm{O}\right)$, TARF: target airflow (lit/sec.), ARES: aerodynamic resistance $\left[\mathrm{cmH}_{2} \mathrm{O} /(\mathrm{l} / \mathrm{s})\right]$, AEFF: aerodynamic efficiency (ppm), C.C.: correlation coefficient, VFI: vocal fatigue index

계적으로 유의미한 상관관계가 없었다.

\section{음성피로도와 공기역학 분석 간 상관분석}

전체 257명에서 PHODB(C.C. $=-0.215, p=0.001$ ), PHOT (C.C. $=-0.137, p=0.028)$ 변수는 부적상관을 보였고, MEAP (C.C. $=0.181, p=0.004)$ 변수는 정적상관을 보였다. 성별을 나눠 살펴보면, 남성군에서 $\mathrm{FVC}(\mathrm{C} . \mathrm{C} .=0.211, p=0.011), \operatorname{MEAF}(\mathrm{C}$. C. $=0.226, p=0.006), \operatorname{TARF}(C . C .=0.212, p=0.011)$ 변수는 정적 상관을 보였고, 여성군에서는 PHODB(C.C. $=-0.248, p=0.008$ ) 변수가 부적상관을 보였다(Table 5).

\section{고 찰}

본 연구는 최근 발표된 음성피로도 설문지와 기존의 음성평 가 항목 간의 상관을 조사한 것으로, 음성피로와 임상가의 청 지각 평가 간에 Grade, Breathiness, Asthenia, Strain 항목에 서 정적상관을 보여, 피로도가 높을수록 음질이 저하되었다. 두 주관적 설문 VHI와 VFI 간 여성과 남성 모든 군에서 강한 정적상관을 보였고 특히 남성군에서 상관계수가 더 높았다. 선행연국에서도 남녀 모두 피로도가 VHI와 관련이 있다고 하였으며 음성피로가 음성사용 불편감과 상당히 긴밀한 관 계임을 알 수 있다.

음향 분석의 주파수관련 변수에서 $\mathrm{F} 0, \mathrm{mFO}$, STD 변수가 정적상관을 보여, 음성피로도가 높을수록 기본주파수가 높 아지고 기본주파수 편차가 커졌다. 선행연굴의 음성피로 유 무에 따른 음향 분석 결과에서 음성피로가 있으면 F0가 높아 져 본 연구결과와 일치한다. 높은 음성피로도와 기본주파수 상승 간의 상관을 보고한 선행연구이에서는 피로도 상승에 따 라 성대의 진동 패턴이 성문이 덜 닫히는 양상으로 변하여, 음
성에 기식성(Breathiness)이 높아져 음향적으로는 기본주파수 가 상승된다고 하였다. 본 연구의 청지각 평가에서도 Breathiness와 음성피로도 간 정적상관을 보였고, 공기역학 변수인 $\mathrm{MEAP}$ 도 정적상관을 보였기 때문에 본 연구에서는 성대진동 모양을 확인하지 않았지만 주관적 측면과 객관적 변수 결과 가 선행연구와 같은 해석을 하도록 뒷받침해 준다.

여성군보다 남성군에서 Tsam 감소가 두드러졌으며 PER 은 남성군에서만 통계적으로 유의미한 감소를 보였다. 분석 되는 발성 내 주기성이 잡히지 않은 구간은 자동으로 제외되 고 주기성이 포착되는 구간만 분석이 되기 때문에 PER 감소 는 곧 음질 저하를 뜻한다. 남성이 여성보다 음성피로도가 높을수록 발성길이가 짧아지고, 발성 내 주기성이 감소된다. Tsam은 부적상관을 보여 음성피로가 높을 경우 발성길이가 짧아졌다고 단편적으로 생각될 수 있다. 하지만 본 연구대상 자가 음성장애환자들이므로 병변의 심각도에 따라서도 초당 누출되는 공기량이 많아지므로 병변의 심각성에 따라 발성길 이가 짧아진다. 그러므로 음성피로도와 Tsam의 부적상관은 음성피로와 병변의 심각성, 이 두 요소 모두를 고려해야 한다. 이런 해석은 Tsam과 같은 결과를 보인 공기역학 변수 중 PHOT 감소에도 동일하게 적용해야 한다.

Jitter 계열의 6개 모든 변수에서 음성피로에 따른 수치 상 승을 보였다. 성별로 나눠 살펴보면, 남성군의 Jitt 평균표표준 편차가 $2.34 \pm 2.95 \%$ 이고, 여성군이 $2.27 \pm 2.07 \%$ 였다. Jitt 상 승은 음성의 주기(period)가 불규칙적으로 됨을 의미한다. 주 기성이 깨지면 음질이 나빠진다. 이는 청지각 평가 결과와도 일치하며 이러한 변화는 여성보다 남성에서 더 두드러졌다.

음성피로가 성대병변을 초래했는지 아니면 성대병변이 음성 피로를 유발하는 것인지에 대해서는 현재의 연구디자인에서 는 알 수 없다. 하지만 남성군과 달리 여성군에서는 음성피로 
도와 주파수변동 음향변수 간의 관련성이 없다는 점을 근거 로 유추해 보면, 여성은 음성피로가 있어도 다른 보상적 작용 으로 발성하였거나 여성의 성대병변이 남성만큼 심하거나 크 지 않아 음향변수와 음성피로 간의 상관이 적게 나타났을 것 으로 생각한다. 이렇듯 남녀가 음성피로와 음향변수 간 차이 점에 대해서는 고려해야 할 점이 있지만, 분명한 것은 음질을 예측하는 주파수변동 관련 변수와 음성피로 간의 상관이 존 재한다.

진폭변동 관련 5개 변수 중 Shim은 남성군에서만 음성피 로와 정적상관을 보였다. 진폭변동 변수들은 공기량(압력) 및 음성 강도에 영향을 쉽게 받으므로 공기역학 변수 변화를 고려 하여 해석할 필요가 있다. 공기역학 변수 중 여성군에서 $\mathrm{PHODB}$ 변수는 음성피로와 부적상관을 보였는데, 이는 음성피로도 가 높을수록 여성은 음성의 강도를 줄여 발성함을 의미한다. 낮은 강도의 음성에서는 강도 변이를 측정하는 Shim 변수의 변화가 적게 나온다. 하지만, 남성군의 경우는 공기역학 변수 중 $\mathrm{MEAF}$ 와 $\mathrm{TARF}$ 변수가 음성피로와 정적상관을 보였다. 이는 남성은 음성피로가 높을수록 오히려 음성의 강도를 증 가시켜 발성한다고 보여진다. 강한 발성의 유지력이 없다면 결과적으로 진폭변동이 커진다. 음성피로에 따라 여성은 음 성 강도를 낮추어 작은 소리로 발성하여 진폭변동률이 적은 반면, 남성은 큰 음성을 사용하지만 강도의 진폭이 일정하지 않은 불안정한 강도의 발성을 보인 것으로 해석된다.

성대와 같이 주기(period)를 갖는 진동자는 배음들(harmonics)을 형성한다. 첫 번째 배음 $(\mathrm{H} 1)$ 이 기본주파수 $(\mathrm{F} 0)$ 에 해당하며, 이 $\mathrm{H} 1$ 이 배가 되는 것이 두 번째 배음 $(\mathrm{H} 2)$ 이고 세 배가 되는 것이 세 번째 배음 $(\mathrm{H} 3)$ 이 된다. 이러한 배음 이외에 존재하는 주기적 진동은 sub-harmonics로 분류된다. 성대 와 같은 단일 진동자에서의 sub-harmonics 존재는 이중음 성 사용자들에게서 나타나는 음성장애로 분류되며, 성대병변 이 있는 음성장애환자에게서 sub-harmonics는 성대병변으 로 인한 성대 외 다른 진동자 형성으로 나타나는 일종의 음성 일탈의 주요 현상이다. ${ }^{11)} \mathrm{DSH}$ 와 NSH 변수가 음성피로도와 정적상관을 보이고 남성군에서만 DUV, NUV 변수에서 정적 상관을 보였다. 이는 음성피로가 높아질수록 음성일탈과 그 정도가 증가한다는 보고 ${ }^{3}$ 와도 일치한다.

소음과 진전관련 변수에서 NHR과 VTI 변수가 음성피로 도와 정적상관을 보인 반면에 SPI 변수는 부적상관을 보였 다. 또한 남성군에서만 추가적으로 FTRI 변수가 정적상관을 보였다. 음성피로와 음성진전 간 정적상관을 보고한 연구에 서, ${ }^{2}$ 음성피로로 인해 발성 노력(vocal effort)이 증가되어 측윤 상피열근(lateral cricoarytenoid muscle)과 성대의 종적 긴 장(longitudinal tension)을 유지시키는 윤상갑상근(cricothy- roid muscle), 성대를 압축시키는 갑상피열근(thyroarytenoid muscle)의 긴장성 변화로 음성진전이 발생한다고 하였다. 본 연구에서도 선행연구의 해석을 지지한다.

이상의 음향분석 결과를 종합해 보면 여성보다 남성에서 음 성피로가 음향적 측면에서의 부정적 영향이 컸음을 알 수 있 다. 선행연구 ${ }^{7)}$ 에서 남성군에서만 음향변수(F0 tremor, shimmer, amplitude tremor)가 피로도와 상관을 보이고 고피로도 군이 저피로도군보다 본 음향변수가 높게 보고되어 피로도에 따른 음질 저하를 보였다. 이는 본 연구 결과를 뒷받침한다.

음향변수를 논할 때 거론한 공기역학 분석 결과를 정리하 면 음성피로가 높을수록 발성 시 평균음압과 최대연장발성시 간이 감소한 반면, 평균음도는 증가하였다. 특히 남성은 음성 피로가 높을수록 호기량, 평균호기류율, 표적 호기류율이 증 가하였고, 여성은 발성 시 음압이 감소하였다. 음성피로도에 따라 공기역학 변수의 남녀 간 차이 또한 확인되었다.

본 연구에서는 성대병변의 심각도에 대한 정보가 없기에 해 석에 한계가 있다. 성대용종, 성대결절, 백반증후군이 159명이 고 이 중 여성이 66명, 남성이 93명으로 남성 비율이 더 높았 다. 일반적으로 여성보다 남성에게서 성대병변이 심한 경우가 흔하기 때문에 병리적 측면에서 남성이 여성보다 성대병변이 심할 수 있다는 점을 고려해야 할 것이다.

본 연구는 최근 발표된 VFI 설문지를 번안하여 음성피로 와 음성평가 항목(청지각, 주관적, 음향, 및 공기역학 평가) 간 의 상관을 살펴보였다. 피로도에 따른 청지각적 음질 저하 간 의 상관관계를 확인하였다. 객관적 음향 평가에서는 여러 변 수에서 상관이 있었으며, 특히 여성보다 남성에서 음성피로에 따른 음성의 음향변화가 더 부정적이었다. 공기역학 측면에 서도 음성피로에 따른 발성 음압 및 평균호기류율, 발성길이 감소를 보였으며, 두 주관적 설문 평가 간 강한 정적상관을 보였다. 고로 한국 음성장애환자의 음성피로도 평가를 위해 본 음성피로도 설문이 임상에서 활용 가능하다. 앞으로 본 설문지가 수술 전후 및 음성치료 효과 검증에 사용될 수 있 다고 생각한다.

\section{Acknowledgments}

I really appreciated all patients who participated in this survey. This work was supported by the Ministry of Education of the Republic of Korea and the National Research Foundation of Korea (NRF-2016S1A5B6914201).

\section{REFERENCES}

1) Welham NV, Maclagan MA. Vocal fatigue: current knowledge and future directions. J Voice 2003;17(1):21-30.

2) Boucher VJ, Ayad T. Physiological attributes of vocal fatigue and their acoustic effects: a synthesis of findings for a criterion-based prevention of acquired voice disorders. J Voice 2010;24(3):324-36.

3) Kitch JA, Oates J. The perceptual features of vocal fatigue as self- 
reported by a group of actors and singers. J Voice 1994;8(3):207-14.

4) Kostyk BE, Putnam Rochet A. Laryngeal airway resistance in teachers with vocal fatigue: a preliminary study. J Voice 1998;12(3): 287-99.

5) Hunter EJ, Titze IR. Quantifying vocal fatigue recovery: dynamic vocal recovery trajectories after a vocal loading exercise. Ann Otol Rhinol Laryngol 2009;118(6):449-60.

6) Eustace CS, Stemple JC, Lee L. Objective measures of voice production in patients complaining of laryngeal fatigue. J Voice 1996;10(2): 146-54.

7) Cho SW, Yin CS, Park YB, Park YJ. Differences in self-rated, perceived, and acoustic voice qualities between high- and low-fatigue groups. J Voice 2011;25(5):544-52.
8) Ilomäki I, Kankare E, Tyrmi J, Kleemola L, Geneid A. Vocal fatigue symptoms and laryngeal status in relation to vocal activity limitation and participation restriction. J Voice 2016 Aug 17 [Epub ahead of print]. http://dx.doi.org/10.1016/j.jvoice.2016.07.025.

9) Nanjundeswaran C, Jacobson BH, Gartner-Schmidt J, Verdolini Abbott K. Vocal fatigue index (VFI): development and validation. J Voice 2015;29(4):433-40.

10) Kang YA, Yoon KC, Kim JO. An aerodynamic and acoustic analysis of the breathy voice of thyroidectomy patients. Phonet Speech Sci 2012;4(2):95-104.

11) Kent RD, Ball MJ. Voice quality measurement. San Diego: Singular Publishing Group;2000. p.126-222. 


\section{Appendix}

\section{Voice Fatigue Index in Koran Version}

다음은 목소리와 목소리가 생활 속에 미치는 영향을 설명하는 것들입니다. 여러분이 얼마나 자주 경험하는지를 최근 1 주 일간의 기억으로 해당하는 숫자에 동그라미 표시를 해주십시오.

\begin{tabular}{|c|c|c|c|c|}
\hline 0 & 1 & 2 & 3 & 4 \\
\hline 결코 그렇지 않다 & 거의 그렇지 않다 & 때때로 그렇다 & 거의 항상 그렇다 & 항상 그렇다 \\
\hline
\end{tabular}

Part I

1. 목소리를 사용한 후에, 나는 말을 하고 싶지 않다.
0
1
2
3
4

2. 말을 많이 할 때, 내 목소리는 지친다(피곤하다, 고단하다).
0
12
3
4

3. 말할 때, 나는 노력을 해야만 한다.
0
12
3
4

4. 말을 하면 내 목소리는 쉰 소리가 된다.
0
12
3
4

5. 말하는 것 자체가 일(노동)처럼 느껴진다.
0
1
2
3
4

6. 목소리를 어느 정도 낸 후에는, 말하는 것이 줄어드는 편이다.
0
12
3
4

7. 내가 많이 말을 해야 할 것 같은 모임(상황)은 피하게 된다.
0
12
3
4

8. 퇴근 후, 나는 가족과 대화할 수 없을 정도다(목이 아파서, 목이 힘들어서).
0
12
3
4

9. 목소리를 어느 정도 내면, 목소리를 내기 위해 노력을 해야 한다.
0
1
2
3
4

10. 나는 목소리를 또렷하게 내는 것이 어렵다.
0
1
2
3
4

11. 목소리 사용 후에는 목소리가 힘 빠지게(약하게) 난다.
0
1
2
3
4

Part II

12. 목소리를 사용한 날의 오후쯤, 목에 통증(아픔)을 경험한다.
0
12
3
4

13. 목소리를 사용한 날의 오후쯤, 목구멍에 통증(아픔)을 경험한다.
0
1
2
3
4

14. 말을 많이 할 때, 목이 아프다.
0
1
2
3
4 
15. 목소리를 낼 때, 목구멍(인후두)이 아프다.

$0 \quad 12$

3

4

16. 목소리 때문에 목 쪽에 불편감이 느껴진다.
0
1
2
3
4

Part III

17. 휴식하면, 목소리는 좋아진다.
0
1
2
3
4

18. 휴식하면, 목소리를 내기 위한 노력이 줄어든다.
0
1
2
3
4

19. 휴식하면, 쉰 목소리가 좋아진다.

0

1

2

3

4 